\title{
Anaphora Resolution of Japanese Zero Pronouns with Deictic Reference
}

\author{
Hiromi Nakaiwa and Satoshi Shirai \\ NT'T Communication Science Laboratories \\ 1-2356 Take, Yokosuka-shi, Kanagawa-ken, 238-03, Japan \\ \{nakaiwa, shirai\}@nttkb.ntt.jp
}

\begin{abstract}
This paper proposes a method to resolve the reference of deictic Japanese zero pronouns which can be implemented in a practical machine translation system. This method focuses on semantic and pragmatic constraints such as semantic constraints on cases, modal expressions, verbal semantic attributes and conjunctions to determine the deictic reference of Japanese zero pronouns. This method is highly effective because the volume of knowledge that must be prepared beforehand is not very large and its precision of resolution is good. This method was implemented in the Japanese-to-English machine translation system, ALT-J/E. According to a window test for 175 zero pronouns with deictic referent in a sentence set for the evaluation of Japaneseto-English machine translation systems, all of zero pronouns could be resolved consistently and correctly.
\end{abstract}

\section{Introduction}

In all natural language, elements that can be easily deduced by the reader are frequently omitted from expressions in texts (Kuno, 1978). This phenomenon causes considerable problems in natural language processing systems. For example in a machine translation system, the system needs to recognize that elements which are not present in the source language, may become mandatory elements in the target language. In particular, the subject and object are often omitted in Japanese; whereas they are often mandatory in English. Thus, in Japanese-to-English machine translation systems, it is necessary to identify case elements omitted from the original Japanese (these are referred to as "zero pronouns") for their translation into English expressions.

Several methods have been proposed with regard to this problem (Kameyama, 1986) (Walker ct al., 1990) (Yoshimoto, 1988) (Dousaka, 1994).
When considering the application of these methods to a practical machine translation system for which the translation target area can not be lim ited, it is not possible to apply them directly, both because their precision of resolution is low as they only use limited information, and because the volume of knowlcdge that must be prepared beforehand is so large.

The zero pronouns that must be resolved by a machine translation system can be classified into 3 types; (a) zero pronouns with antecedents within the same sentence (intrasentential), (b) zero pronouns with antecedents elsewhere in the text (intersentential) and (c) zero pronouns with deictic reference (extrasentential). Regarding type (b), Nakaiwa and Ikehara (1992) proposed a method to determine the intersentential antecedents using verbal semantic attributes. The rules used in this method are independent of the field of the source text. Therefore, anaphora resolution may be conducted with a relatively small volume of knowledge, making the proposed method very suitable for machine translation systems. Iurthermore, for type (a), Nakaiwa and Ikehara(1995) proposed a method to determine the intrasentential antecedents of Japanese zero pronouns using semantic constraints such as verbal semantic attributes and pragmatic constraints such as types of conjunctions and modal expressions.

In this paper, we propose a widely applicable method to determine the deictic referents of Japanese zero pronouns (type (c)) using not only semantic constraints to the cases but also further semantic constraints such as verbal semantic attributes and pragmatic constraints such as modal expressions and types of conjunctions.

\section{Appearance of Zero Pronouns in Japanese Texts}

In order to understand the distribution of zero pronouns with antecedents that do not appear in the text, in this section, we examine which zero pronouns must be resolved and where their antecedents appear, using a test set designed to evaluate the performance of Japanese-to-English ma- 
chine translation systems (Ikehara ct al., 1994). 'The results of the examination of zero pronouns and their referential elements in the functional test sentence set (3718 sentences) are shown in Table 1. There were a total of 512 zero pronouns in 463 sentences. 'The location of referential clements can be divided into 2 kinds: those expressed in the same sentence, and those not expressed in the same sentence. 'The labter were further classilied into 6 kinds.

- The zero pronoun is not translated because the passive voice is used.

- 'The referent is the writer or spcaker, $I$ or a group, we.

- 'l'he referent is the reader or hearer, you.

- The referent is liuman but it is not known who the human is.

- T'he zero pronoun shonld be translated as it.

- The referent is another specific; element.

According to this study of the functional test sentence set, in 373 out of 512 instances $(73 \%)$ the antecedent was not expressed in the sentence. Zero pronouns could be left unexpressed by converting the translation to the passive voice in 173 instances $(34 \%)$. The other zero pronoms, 200 instances $(39 \%)$, referred to antecedents that did not appear in the sentence. In 69 out of the 200 instances (13\%) zero pronouns were the subject of the sentence and referred to the writer or speaker $I$ or a group we. Further examination revealed that only in these 69 instances did the verb that governed them express some modality such as shilai '- want to -' or -shiyou 'Tet us -' or the verbs were omou 'think' and other such words indicating 'THINking ACTION'. Furthermorc, zero pronouns that were the subjects and that referred to the reader or hearer you, amounted to 28 out of the 200 instances (5\%). In these 28 instances, the verbs that governed these zero pronouns expressed the modalities of - subekida 'should' or -sitehanaranai 'must not'. Similarly, modalities and verb types can be used to identify it or the 'unknown human'. 'I'his type of zero pronoun can be resolved by deducing their referents using modality or categorized verbal semantic attributes.

\section{Deictic Resolution of Japanese Zero Pronouns}

Based on the results shown in section 2 , we propose a method to resolve Japanese zero pronouns whose antecedents do not appoar in the texts.

\subsection{Deictic Resolution using Semantic Constraints on Cases}

'lo resolve Japanese zero pronouns whose antecedents do not appear within the texts, it is possible to use the semantic constraints on verbs' case
'Table 1: Distribution of zero pronouns and their referential elements

\begin{tabular}{|c|c|c|c|c|c|c|c|c|}
\hline \multirow{3}{*}{$\begin{array}{l}\text { Luc. } \\
\text { of } \\
\text { zero } \\
\text { pron. }\end{array}$} & \multicolumn{7}{|c|}{ Lox. of 'referential elements' } & \multirow{3}{*}{$\begin{array}{l}\text { l'o- } \\
\text { tal }\end{array}$} \\
\hline & \multirow{2}{*}{$\begin{array}{l}\text { Intra- } \\
\text { sent- } \\
\text { ential }\end{array}$} & \multicolumn{6}{|c|}{ Deictic } & \\
\hline & & Psve & $\begin{array}{c}1 \\
\text { we }\end{array}$ & you & $\begin{array}{l}\text { hil- } \\
\text { man }\end{array}$ & it & $\begin{array}{l}\mathrm{mb} \\
\mathrm{sc}\end{array}$ & \\
\hline hat & $T$ & 5 & 0 & 0 & 0 & 2 & 0 & 8 \\
\hline$g a$ & 128 & 166 & 69 & 28 & 25 & 50 & 3 & $4 \overrightarrow{69}$ \\
\hline$o$ & 8 & 0 & 0 & 0 & 0 & 11 & 0 & 19 \\
\hline$n i$ & 1 & 2 & 2 & 5 & $\overline{0}$ & 0 & 2 & 12 \\
\hline misc & 1 & 0 & 1 & 1 & 0 & i & 0 & 4 \\
\hline Total & 139 & & & & & & & $5 \overline{12}$ \\
\hline
\end{tabular}

clements to deduce likely referents. 'The semantic information used to estimate supplementing clements is similar to the constraints on cases used for selocting the transfer patterns in a machino translation system. Figure 1 shows an cxample of a transfer pattern in a Japanese-to-linglish machine translation system for the Japanese verb $i k i$ masu 'go'. Figure 1 shows how, if the Japanese verb is ikimasu 'go' and the noun phrase with a ga particle, which shows a subject, has the semantic attribute SUBJECT, VHIICLAS OR ANIMALS, then the verb should be translated as 'go'. In this pattern, if the subject $\mathrm{N} 1$ becomes a zero pronoun, the system tries to estimate the roferent using semantic constraints. But, in this case, it is impossible to estimate the referent as one type, because there are threc kinds of semantic constraints. In the transfer pattern, the semantic constraints are loft unfulfilled if they aro not used in solecting the appropriate translation. So, this method frequently poses difliculties in pinpointing elements to be ostimated.

According to the results that were examined in section 2 , this type of zero pronoun can be resolved by deducing their referents not only using semantic constraints to the cases but also using modality or categorized verbal semantic attributes. For example, in this case, it is effective to determine the referents corresponding to ' $\mathrm{T}$ ' using the verbal semantic attributes of the pattern, N1's I'IIYSICAr, 'IRANSlien and the polite expression - masu.

$$
\begin{gathered}
\text { NI(SUB.JECT'S, VEHICLES OR. ANIMALS)-ga } \begin{array}{c}
\text { iki-masu } \\
\text { No-POLITE }
\end{array} \\
\Rightarrow \text { NI go. }
\end{gathered}
$$

Figure 1: Japanese-to-Linglish transfer dictionary

\subsection{Deictic Resolution using Semantic and Pragmatic Constraints}

According to the analysis of the results shown in section 2, we found that modal expressions and verbal semantic attributes are uscful in cletermining the deictic referents of Japanese zero pronouns. Also, we can estimate the types of conjunctions that are effective in determining the rel- 
erents in a complex sentence. In this section, we examine three kinds of semantic and pragmatic constraints, modal expressions, verbal semantic attributes and conjunctions.

\subsubsection{Constraints Based on Modal Expressions}

Modal expressions in Japanese are expected to be the most powerful constraints for estimating deictic reference. For example, in the case of zero pronouns in ga-cases 'subject,', the referent becomes the writer or speaker, $I$ or a group, we if the sentence has the modal expressions, -sitai ' $\phi$ want to -' HOPL or -silchosii ' $\phi$ want $\phi$ to -' CaUsn'TVF Holk; the referent becomes the reader or hearer, you if the sentence has the modal expressions, siteha-ikenai ' $\phi$ must not -' PRomInIT or -subckida ' $\phi$ should -' obliga'rion. If there are no referent candidates found within the surrounding text, the referents can be determined using the previous constraints based on modal expressions.

\subsubsection{Constraints based on Verbal Semantic Attributes}

Constraints based on verbal semantic attributes can be divided into the following two types:

(1) Constraints based on the types of verbs 'Give and take' expressions such as the verbs morau 'get' and yaru 'give' and transfer expressions such as the verbs ik'u 'go' and kuru 'come' can determine the referents of zero pronouns without modal expressions. lior example, if the ga-case (subject) of the sentence whose verb is morau 'get' becomes a zero pronoun, the refcrent becomes $I$. In the case of verb kuru 'come', the referent becomes an element other than $I$, for examplo you. These kinds of verbs implicitly indicate the relationship between the writer/speaker and the referent of the ga-case (for example, the empathy (Kuno, 1978) or the side of the territory of information (Kamio, 1985)). Based on these properties, the deictic referents of Japanese zcro pronouns can be estimated.

(2) Constraints based on the types of verbs and modal expressions

Even if the referents of zero pronouns can not be determined using modal exprossions or the types of verbs, the referents can sometimes be determined using a combination of modal expressions and the types of verbs. For example, in the following Japanese expression, the ga-case becomes a. zero pronoun.

$$
\begin{gathered}
\text { hon-wo yon-da } \\
\text { b-SUBJ book-oBJ read-PAST } \\
\text { I read a book. }
\end{gathered}
$$

In this sentence the experience of the writer/speaker, $I$ is suitable for the reference of the zero pronoun. As shown in this sentence, if the ga-case in an expression with a verb whose semantic attribute is $\Lambda C^{\prime} \Gamma \mathrm{T}$ N and modal expression is -ta PAST, becomes a zero pronoun, it will be translated by a human translator as $I$. In a similar way, if the ga-case in an expression with a verb whose semantic attribute is ACIION and modal expression is - durou 'will' Est'IMA'Tron, becomes a zero pronoun, the referent is you. Such constraints using both verbal semantic a.tributes and modal expressions can be used to determine the deictic reference of Japanese zero pronouns.

To write constraints based on types of verbs effectively, we used the 97 verbal semantic attributes (VSA) proposed by Nakaiwa (1994).

\subsubsection{Constraints based on Conjunctions}

Sometimes the deictic referents of Japanese zero pronouns can be determined elepending on tho types of conjunctions. 'I'he constraints based on the Japanese conjunctions can be divided into tho following two types.

(1) The constraints on case sharing depending on the types of conjunctions

Minami (1974) and 'lakubo (1987) proposed that different Japanese conjunctions cover or share different cases. For example Minami divided Japanese conjunctions into three kinds, $\Lambda, B$ and C. A complex sentence which includes $A$ type Japanese conjunctions, such as tsutsu 'while' and nagara 'while', shares one ha-case ('Iopic) and one ga-case (Subject). In the case of B type Japanose conjunctions, such as node 'because' or tara 'if', one ha-case is shared but not the ga-case. In the case of $\mathrm{C}$ type Japanese conjunctions, such as keredo 'but' or kedo 'but', neither the ha-case nor the ga-case are necessarily shared. According to this classification, if two ga-cases in a complex sentence joined by an $\Lambda$ type Japanese conjunction were to become zero pronouns and the referent of one of the two zero pronouns was determined by the constraints proposed previously, then the referent of the other zero pronoun is the same refercnt. These characteristics of Japanese conjunctions can be used to determine the referents of zero pronouns.

(2) Constraints bascd on conjunctions, modal expressions and verbal semantic attributes

Sometimes co-occurrence of conjunctions, verbal semantic attributes and modal expressions in a complex sentence determines the meaning of the sentence, and sometimes they determine the deictic reference of zero pronouns in the sentence. For example, in the following Japanese expression, the subject of the verb ika-nai 'go-not' becones a zero pronoun but the referent can be determined as the writer or speaker, you

$$
\begin{aligned}
& \text { tokoya-ni } \text { ika-nai to, } \\
& \phi \text {-subJ barber-no-onj go-not if } \\
& \text { If you don't go to the barber, } \\
& \text { kami-ga boubou-ni-naru } \\
& \text { hair begin to look untidy } \\
& \text { your hair will begin to look untidy. }
\end{aligned}
$$


This sentence has the meaning that the writer or speaker actvises that if you do not do something, a situation will arise. 'The meaning type of a complex sentence can be determined using the rules that the conjunction is to 'if' and in the sub clause ga-caso becomes a zero pronoun and the moaning of the verb is $\Lambda C^{\prime} C^{\prime} I O N$ with negation and in the main clause the moaning of the verb is $\Lambda^{\prime} T-$ 'TrIBute with modal expression ni-naru 'become' A'T'R'RIBUT'T' 'TRANSE'ER.

'The meaning type of a complex sentence can be determined using the folowing rules: when the conjunction is 'if' and the sub clause gatcase becomes a zero pronoun, and the meaning of the verb is Ac'lon with negation, and in the main clause the meaning of the verb is A'TRRIBU'l's with modal expression, then ni-naru 'become' is an example of A'T'TRIBUTF TRANSFER. Using these kinds of rules, the meaning types of complex sentences can be determined, and the reference of zero pronouns can be retermined.

\subsection{Algorithm}

In this subsection, we propose an algorithm for the deictic resolution of Japanese zero pronouns using the constraints proposed in this section. This algorithm was implemented in a Japanescto- English machine translation system, so the only zero pronouns that must be resolved are those that become mandatory elements in Finglish. 'Io realizo the previously proposed conditions in an algorithm, we must consider cases when these antecelents exist in the same sentence as well as when these antecedents exist, in another sontences in the text, and we must design the algorithm to increase the overall accuracy of the resolution of zero pronouns.

Anaphora resolution of zero pronouns is conducted as follows. In each step in the algorithm, when the referential element within or withont the text is determined, the system checks not only the conditions that are written in the following algorithm, but also the semantic conditions that verbs impose on zero pronouns in the case elements in cach pattern of the Japanese-to-Finglish transfer dictionaries.

1) Detection of zero pronouns. If they exist, proceed to step 2.

2) Exannine whether there are antecedents within the same sentences. (For example, anaptora resolution is performed using Nakaiwa's method (Nakaiwa and Ikehara, 1995)).

If their antecedents can be found, finish the resolution process. Else, proceed to step 3.

3) Examine whether there are antecedents within other sentences in the text. (For example, anaphora resolution is performed using Nakaiwa's method (Nakaiwa and Ikehara, 1992)) If their antecedents can bo found, finish the resolution process. Filse, procecd to step 4.
4) Deictic: resolution of Japanese zero pronouns using verbal semautic attributes, modal expressions and the types of conjunctions arc conducted. The conditions to determine the referents are summarized in 'Table 2.

If their referents can be found, liuish the resolntion process. Blse, procced to step 5.

5) If referential elements can not be found and tho text can be translated successfully in the passive voice, translate in the passive voice.

lilse, based on the semantic restrictions imposed on the zero pronoun by the verbs, deductively generate anaphora elements.

Finish the rcsolution process.

'Table 2: Resolution conditions of deictic referents

\begin{tabular}{|c|c|c|c|}
\hline $\begin{array}{l}\text { Idoca- } \\
\text { tion of } \\
\text { Zero } \\
\text { Pron. }\end{array}$ & Condition & $\begin{array}{l}\text { Ref- } \\
\text { ere- } \\
\text { nts }\end{array}$ & Comment \\
\hline \multirow{12}{*}{$\begin{array}{c}q a- \\
\text { (sust } \\
(\text { subj) }\end{array}$} & mortal hope(-sitar $)$ & \multirow{4}{*}{$\begin{array}{l}\text { I } \\
\text { or } \\
\text { we }\end{array}$} & spoaker/writer hopes \\
\hline & $\begin{array}{c}\text { modal causal hope } \\
\text { (-sitetosit) }\end{array}$ & & $\begin{array}{l}\text { spoaker/writer hopes } \\
\text { to hearer/reader }\end{array}$ \\
\hline & $\begin{array}{l}\text { modalinvite } \\
(- \text { sinashou })\end{array}$ & & $\begin{array}{l}\text { speaker/writer } \\
\text { invites }\end{array}$ \\
\hline & $\begin{array}{c}\text { VSA:under action } \\
\text { +modal:polite } \\
\text { (-simusu) }\end{array}$ & & $\begin{array}{l}\text { depending on the } \\
\text { social relationslips } \\
\text { between } \\
\text { speaker/writer and } \\
\text { henrer/reader }\end{array}$ \\
\hline & $\begin{array}{l}\text { modal:prohibit } \\
(- \text { siteha-ikenai })\end{array}$ & \multirow[t]{3}{*}{ you } & $\begin{array}{l}\text { speaker/writer } \\
\text { prohibits hearer/ } \\
\text { ruader's action }\end{array}$ \\
\hline & $\begin{array}{c}\text { VSA uncler action } \\
+ \text { modal:obligation } \\
(\text {-behi) }\end{array}$ & & $\begin{array}{l}\text { speaked writer } \\
\text { make hearer/readro's } \\
\text { artion obligation }\end{array}$ \\
\hline & …....... & & .............. \\
\hline & $\begin{array}{l}\text { VSA: } \\
\text { bodily action } \\
\text { thinking action } \\
\text { emotive action } \\
\text { emotive state } \\
\text { bodily transfer }\end{array}$ & \multirow[t]{2}{*}{$\begin{array}{l}\text { hu- } \\
\text { man } \\
(\mathrm{I} \\
\text { we, } \\
\text { you, } \\
\ldots \text { ) }\end{array}$} & $\begin{array}{l}\text { When the verb that } \\
\text { show the action or } \\
\text { emotion that only } \\
\text { human can do } \\
\text { appears in the sent- } \\
\text { ence and when there } \\
\text { are noother referent } \\
\text { candidates, the ref- } \\
\text { erents of zero pron- } \\
\text { ouns is human }\end{array}$ \\
\hline & ……... & & \\
\hline & $\begin{array}{l}\text { VSA copula sent- } \\
\text { ence and the mean. } \\
\text { ing is abstract }\end{array}$ & \multirow[t]{3}{*}{ it. } & $\begin{array}{l}\text { Pronoun of abstract } \\
\text { noun should be it }\end{array}$ \\
\hline & $\begin{array}{l}\text { VSA:attribute and } \\
\text { perceptual state }\end{array}$ & & $\begin{array}{l}\text { verbs that indicates } \\
\text { weather such as atsui } \\
\text { 'hot', -samut 'cold' }\end{array}$ \\
\hline & …….... & & …......... \\
\hline \multirow[t]{2}{*}{$\begin{array}{l}n i- \\
\text { case } \\
\text { (ind. } \\
\text { obj.) }\end{array}$} & $\begin{array}{l}\text { Inodal: } \\
\text { causal hope } \\
\text { (-sitehosit) }\end{array}$ & \multirow[t]{2}{*}{ you } & $\begin{array}{l}\text { speaker/writer hopes } \\
\text { to hearer/reader }\end{array}$ \\
\hline & . $\quad \ldots \ldots \ldots \ldots$ & & ……..... \\
\hline
\end{tabular}

\section{Evaluation}

\subsection{Evaluation Method}

In this section, we show the results of evaluation of the method that was proposed above. The method to resolve zero pronoms with deictic reference was tested using the Japanese-to-Linglish machine translation system ALI'J/E (Ikehara et al., 1991). 'T'he criteria for the evaluation and procedures used were as follows. 


\subsubsection{Resolution Target}

The target was to resolve successfully the five types of zcro pronouns (ga-case « "I" or "we", gacase $\leftarrow$ "you", ga-case $\leftarrow$ HUMAN, ga-case $\leftarrow$ "it" , ni-case $\longleftarrow$ "you"; 175 instances). T'hese are the zero pronouns with deictic reference found within the 512 zero pronouns in the 3718 sentence set for the evaluation of Japanese-to-English machine translation systems.

\subsubsection{Rules to Resolve Zero Pronouns}

The rules to resolve 175 zero pronouns were created by examining these zero pronouns using the constraints discussed in section 3 (16 rules) ${ }^{1}$.

\subsubsection{Tests for the Evaluation}

'To examine the relationship between conditions of resolution and accuracy of resolution, we conducted the following two tests.

(1) Resolution accuracy for conditions of resolution

We examined the accuracy of resolution depending on the types of conditions in anaphora resolution such as semantic constraints to the cases, modal expression, verbal semantic attributes and conjunctive expressions. We cvaluated the accuracy depending on the types of constraints used.

(2) Resolution accuracy for rule complexity We examined the accuracy of the resolutions to see how they were affected by the complexities of the rules that were used in the resolution. In this test we evaluated the accuracy using simple, easily created and universal rules.

\subsection{Resolution Accuracy for Conditions of Resolution}

To examine the resolution accuracy under different conditions, we examined the accuracy of the method proposed in this paper with the following 4 kinds of conditions:

- using conditions of semantic constraints on cases only

- using conditions of semantic constraints on cases and modal expression

- using conditions of semantic constraints on cases, modal expression and verbal semantic attributes

- using conditions of semantic constraints on cases, modal expression, verbal scmantic attributes and conjunctious

'Table 3 shows the results of the resolution depending on the types of the rules. As shown in

\footnotetext{
${ }^{1}$ At the moment, it is difficult to use sentences which were not successfully syntactically and semantically analyzed for the evaluation of our method. So, to evaluate the technical limitation of proposed method, we evaluated the resolution accuracy in the sentences which were examined to make the 46 rules (window test). We will conduct blind tests after we have finished debugging the whole system.
}

this table, all 175 yero pronouns can be resolved using the rules that werc proposed in section 3 . The introduction of verbal semantic attributes has achieved the same accuracy of resolution as the introduction of modal expressions (41 entries, $24 \%$ ). From this result, we can say that the verbal scmantic attributes are comparatively as effective as modal expressions. 'The results also show that , without using the constraints of conjunctions, the accuracy achicved is as high as $85 \%$.

\subsection{Resolution Accuracy against Rule Complexity}

To examine how the resolution accuracy varied according to the complexity of rules, we tested the accuracy of the method proposed in this paper at different levels of complexity. 'The complexitics $\mathrm{C}$ were evaluated using the following formula, and depended on the number of constraints used.

$\mathrm{C}=$ \# of modal const. ${ }^{*} 1+$ \# of VSA const. ${ }^{*} 1$

+ \# of conjunctions const. ${ }^{*} 2$

In this formula, 1 in the modal and VSA and 2 in the conjunction indicate the weights. Because conjunction constraints aflect both sides of the unit sentence, we gave the conjunctions constraints a weight of 2 . According to this formula, the complexity of a rule that has a constraint for conjunctions and for $\operatorname{VS} \Lambda$ in the main clause and for modal and VSA in the sub clause, becomes $5(=$ $\left.1(\text { modal })^{*} 1+1(\text { VSA })^{*} 2+2(\text { conjunction })^{*} 1\right)$.

Table 4 shows the accuracy of the resolution depending on the complexitics of the rules. 46 kinds of rules were used in the deictic resolution of 175 zero pronouns as shown in table 4. 'The accuracy of resolution using rules with complexities of 3 or less, is $90 \%$, and the accuracy of resolution using rules with complexities of 4 or less, is $95 \%$. This result shows that the use of the constraints based on modal expressions, VSA and conjunctions can achieve high accuracy using relatively simple rules.

\section{Conclusion}

This paper proposes a powerful method for the resolution of Japanese zero pronouns with deictic reference. It was found possible to resolve all of the sentences in the window test where the referential elements wore not in the sentence resolved. 'This was achieved by the introduction of rules based on four kinds of constraints: semantic constraints on cases, modal expressions, verbal semantic attributes and conjunctions. In the future, we will examine the universality of the rules that have been discussed in this paper by applying them to other texts and examine a method for automatically acquiring the rules needed to resolve zero pronouns with deictic references.

Acknowledgments: We would like to thank Professor Satoru Ikehara of Tottori University for providing valuable comments and suggestions. 
Table 3: Resolution accuracy for conditions of resolution

\begin{tabular}{|c|c|c|c|c|c|c|c|c|c|}
\hline \multirow{2}{*}{$\begin{array}{c}\text { Tocation } \\
\text { of \%ero } \\
\text { Pronouns }\end{array}$} & \multirow{2}{*}{\multicolumn{2}{|c|}{ Reforents }} & \multicolumn{7}{|c|}{ Resolution Condition } \\
\hline & & & \multicolumn{2}{|c|}{$\begin{array}{c}\text { Somtic Constiants } \\
\text { on Cases }\end{array}$} & \multicolumn{2}{|c|}{ + Modal Jixpression } & \multicolumn{2}{|c|}{$+\overline{V S A}$} & T Conjunction \\
\hline \multirow{7}{*}{$\begin{array}{l}\text { ga-case } \\
(\text { subj })\end{array}$} & \multicolumn{2}{|c|}{ Tor $\overline{\mathrm{We}}$} & $23 \%$ & (16) & $58 \%(+35 \%)$ & $(40)$ & $93 \%(+3 x \%)$ & $(64)$ & $100 \%(+7 \%)$ \\
\hline & \multicolumn{2}{|c|}{ you } & $0 \%$ & $(0)$ & $13 \%(+43 \%)$ & (12) & $61 \%(+18 \%)$ & $(17)$ & $100 \%(+39 \%)$ \\
\hline & \multirow{4}{*}{$\begin{array}{l}\text { hu- } \\
\text { maul }\end{array}$} & $\mathrm{I}$ & $6 \%{ }^{-}$ & $(0)$ & $0 \%$ & $(0)$ & $67 \%(+67 \%)$ & $(6)$ & $100 \%(+33 \%)$ \\
\hline & & you & $0 \%$ & $(\overline{0})$ & $0 \%$ & (i) & $55 \%(+55 \%)$ & $(6)$ & $100 \%(+15 \%)$ \\
\hline & & one & $0 \%$ & $(0)$ & $0 \%$ & $(0)$ & $-0 \%$ & $(0)$ & $100 \%(+100 \%)$ \\
\hline & & Sum & $0 \%$ & $(0)$ & $0 \%$ & (0) & $49 \%(+49 \%)$ & (12) & $100 \%(+51 \%)$ \\
\hline & \multicolumn{2}{|c|}{ it } & $100 \%$ & (50) & $100 \%$ & $(50)$ & $100 \%$ & $50)$ & $-100 \%$ \\
\hline $\begin{array}{c}\text { ni-ciase } \\
\text { (ind dobj.) }\end{array}$ & \multicolumn{2}{|c|}{ Yol1 } & $0 \%$ & $(0)$ & $100 \%$ & (5) & $100 \%$ & $(5)$ & $100 \%$ \\
\hline \multicolumn{3}{|c|}{ Sum } & $38 \%$ & (66) & $61 \%(+24 \%)$ & $(107)$ & $85 \%(+24 \%)$ & $(1 \overline{4} 8)$ & $100 \%(+15 \%)$ \\
\hline
\end{tabular}

'Iable 4: Resolution accuracy for complexitjes of rules

\begin{tabular}{|c|c|c|c|c|c|c|}
\hline \multicolumn{3}{|c|}{ Tesolution Condition } & \multirow{2}{*}{$\begin{array}{l}\text { Complexities } \\
\text { of llules }\end{array}$} & \multirow{2}{*}{$\begin{array}{l}\text { Number } \\
\text { of Rules }\end{array}$} & \multirow{2}{*}{\multicolumn{2}{|c|}{ Accuracy }} \\
\hline Modal rixpression & VSA & Conjunctions & & & & \\
\hline 0 & 0 & 0 & $\begin{array}{l}\text { O(Only semantic const- } \\
\text { mints to cases) }\end{array}$ & 0 & $38 \%$ & $(66)$ \\
\hline 1 & 0 & 0 & $-1--1$ & $1](+11)$ & $61 \%(+24 \%)$ & $(107(+41))$ \\
\hline 0 & 1 & 0 & 1 & $12(+1)$ & $62 \%(+1 \%)$ & $(108(+1))$ \\
\hline 1 & 1 & [) & 2 & $29(+17)$ & $85 \%(-1.24 \%)$ & $(148(+40)$ \\
\hline 0 & 0 & 1 & 2 & $30(+1)$ & $85 \%(+1 \%)$ & $(110(+1))$ \\
\hline 1 & 0 & 1 & 3 & $31(+1)$ & $86 \%(+1 \%)$ & $(151(-2))$ \\
\hline 0 & 1 & 1 & 3 & $34(+3)$ & $90 \%(+3 \%)$ & $(157(-+6))$ \\
\hline 1 & $\mathrm{~J}$ & 1 & 4 & $36(+2)$ & $93 \%(+3 \%)$ & $(163(-6))$ \\
\hline 0 & 2 & 1 & 1 & $39(+3)$ & $95 \%(+2 \%)$ & $(167(+1))$ \\
\hline 2 & 1 & 1 & 5 & $40(+1)$ & $90 \%(+1 \%)$ & $(168(+1))$ \\
\hline 1 & 2 & 1 & 5 & $14(+1)$ & $99 \%(+3 \%)$ & $(173(+5))$ \\
\hline 2 & 2 & 1 & 6 & $46(+2)$ & $100 \%(+1 \%)$ & $(175(+2))$ \\
\hline
\end{tabular}

\section{References}

Konji Dousaka. 1994. Identifying the Referents if Japanese Zcro-P'ronouns based on P'ragmatic Condition Interpretation. In Trans. of IPS' Japan, 35(10):768 778. In Japanese.

Satoru Ikehara, Masahiro Miyazakj and Akio Yokoo. 1991. Semantic Aualysis Dictionasy for Machine 'Iranslation. In Technical Reports of SlG on NIIP, NI,-84-13, IPS Japan. In Japanese.

Satoru Ikchara, Shirai Satoshi and Kentaro Ogura. 1994. Criteria for livaluating the Jinguistic Quality of Japanesc-to-linglish Machine 'Iranslation. In Journal of JSAL, 9(5):569-579.

Satoru Ikehara, Shirai Satoshi, $\Lambda$ kio Yokoo and Hiromi Nakaiwa. 1991. 'Loward M'T system without Pre-Lditing - Lfects of New Methods in AIT'-J/E-. In Proc. of M'T'Summit III, pages $101-106$.

Megumi Kameyama. 1986. A property-sharing constraint in centering. In 24th Annual Meeting of $A C L$, pages $200 \cdots 206$.

Akio Kamio. 1985. Danwa ni okeru Shiten. Nihon-go gaku, 4(12):10-21. 'l'aishukan Publ. Co., Tokyo. In Japanese.

Susumu Kuno. 1978. Danwa no Bunpoo. 'Taishukan Publ. Co., Tokyo. In Japanese.

Fujio Minarni. 1974. Gendai Nihon-go no Kouzou. Taishukan Publ. Co., Tokyo. In Japanese.
Hiromi Nakaiwa and Satoru Ikehara. 1992. Zero Jronoun Resolution in a Japanese-to-Hnglish Machine Translation System by using Verbal Semantic Attributes. In Proc of ANLP9O, pages $201208, \Lambda C \mathrm{C}$.

Miromi Nakaiwa, Akio Yokoo, and Saboru Mkehara. 1994. A System of Verbal Semantic Attributes locused on the Syntactic Correspondence between Japanese and English. In Proc. of COL ING94, pages 672 678.

Hiromi Nakaiwa, and Saloru Ikehara. 1995. In trasentential Resolution of Japanese Zero Pronouns in a Machine Translation system using Semantic and Pragmatic Constraints. In Pro. ceedings of TMI95, pages $96-105$.

Yukinori 'lakubo, 1987. 'Tougo Kouzon to Bunmyaku Jyouhou. Nihon-go gaku, 4(1.2):10)21. In Japanese.

Marilyn Walker, Masayo lida and Sharon Cote. 1990. Centering in Japanese 1)iscourso. In Proce of COLING90.

Kei Yoshimoto. 1988. Idcntifying Zero Pronouns in Japanese Dialogue. In Proc. of COLING88, pages 779784 . 